\title{
Introduction: From democracy decline to democracy renewal
}

\section{FAREWELL TO THE ILLUSIONS AND THE NEW HOPES FOR DEMOCRACY RENEWAL}

The dramatic decline of democracy in East-Central Europe (ECE) has attracted great interest worldwide, both in the circle of leading politicians and among social scientists. Going beyond the usual narrow spectrum of the extensive literature on this topic, this book offers a comprehensive analysis of the ECE region, covering the three big social subsystems the socio-economic, legal-political and cultural-civilizational dimensions - in their interactions to explain the reasons for the collapse of ECE democratic systems in the 2010s. The book does not deal with the individual ECE countries - the Czech Republic (CZ), Hungary (HU), Poland (PL), Slovakia (SK) and Slovenia (SI) - separately, but outlines the general features and the historical trajectory of the ECE region in last 30 years, from the very beginning of systemic change in 1989 until the end of 2018, in the two big stages of 'chaotic democracy' and 'authoritarian populism', with a turning point around 2010. Finally, starting from the decline in democracy, the book indicates the perspectives for democracy renewal in ECE in the period of the New World Order and the continued federalization of the EU.

This Introduction gives the theoretical summary of the whole book, the 'bare bones' or description of its conceptual framework and basic terms in outline, focusing on Europeanization and democratization in ECE. It turns against the 'Western fallacy' as an easy dream of creating a carbon copy of the West through a relatively short and painless evolutionary catching-up process. My earlier books (Ágh, 1998a, 1998b) were written in a rather optimistic mood about the enormous historical progressive transformations in ECE in the years of democratic transition when the focus was on the big legal-constitutional transformations. No doubt the Great Transformation - using the term of Karl Polanyi ([1944] 2001) - in ECE has meant a progressive historical turning point for Euro-Atlantic integration, as has been discussed in a literature of library size. But this 
easy-dream scenario has evaporated with the former 'sunny-side presentations' of the democratization cum Europeanization narrative, and nowadays it is high time to discover and describe systematically the shadowy side of the process. Three decades after the system change in 1989 the main task of this book - based on my recent writings (Ágh, 2014-2018) - is to answer the question of why ECE democracy finally collapsed in the 2010s.

Owing to the drastic decline in democracy leading to its collapse, the need for reconceptualization, through elaborating the ECE developments in a new conceptual framework, has arisen. It involves a critical overview of the basic terms from the former optimistic scenario and introduction of a new specific concept instead, with strange terms and a series of paradoxes fitting the ECE developments. First of all, the former idea and practice of democratization from above have to be drastically changed to democratization from below as redemocratization with sustainable development and social progress in an innovation-driven economy. The new conceptual framework presupposes two lines of analysis, deeply interwoven: international dynamism - in the world system and the EU - on one side, and the domestic evolution of the ECE region on the other. This Introduction summarizes the new conceptual framework in outline, including the main ideas and terms of these external and internal processes. The whole concept is developed throughout the book and summarized in Chapter 9 in great detail.

The decline of democracy in ECE has been a long and controversial process in the last quarter-century. The marked process of a 'roll-back in Europeanization' has been intensified by the global crisis, and the de-Europeanization and de-democratization process in ECE has become a significant part of the general polycrisis in the EU. This backsliding of democracy in ECE as a topical issue has usually been analysed in terms of the macro-politics of formal-legal state institutions as well as in GDP terms of macro-economics. The biggest backsliding of democratization, however, has been in the case of political actors and movements, at the meso- and micro-levels of society, resulting in a lack of public participation by citizens in politics, and in eroding trust in the political system due to the failure of the catching-up process. Finally, this decreasing systemic trust in the ECE governments and political elites - which has been largely neglected in the usual analyses - has led to a decline of democracy in ECE, generated by a socio-economic decline that will be summarized in terms of triple crisis. Therefore a comprehensive analysis is needed of the ECE countries, which can be outlined in the following main points. 
First, the decline of democracy of the ECE region has great relevance for international political science and scholarship. The failure of the parallel processes of Europeanization and democratization within the EU in the overview of new core-periphery divide or East-West tension gives a new impetus to European studies. In this book the main EU actors, and most developed states, are called West, while the new member states (NMS) - especially in ECE - are labelled East, and finally the Southern member states are designated South. The analysis of the ECE region is a two-level game or a 'nested game', since this region can only be studied in the context of EU developments, including the 'globalization cum regionalization' around the EU, with special regard to the West Balkan and the East European region. Hence, the study of the ECE region presupposes an analysis of the EU as a whole in its present transition from the Old World Order (OWO) to the New World Order (NWO) in the 2010s.

Second, the decline of democracy in ECE offers new perspectives for the analysis of comparative politics, in both democracy and regional studies. The third wave of democratization was most marked in the ECE region in the 1990s, and its erosion was also most drastic in this region. Therefore, the ever increasing debate about the decline of democracy worldwide has focused to a great extent on ECE too, or in general on the NMS. There have been two main stages in recent ECE history - in outline before and after the global crisis, with three periods of historical trajectory, in the decades of the 1990s, 2000s and 2010s - that give the structure of the book, which concentrates on the second stage since 2010. The turning point around 2010 indicates the crisis of crisis management in ECE, with the transition from soft to hard populism marking the deep decline of democracy, or the emptying of democracy through the introduction of the soft or hard authoritarian systems. These ECE processes have also been closely connected with the Europeanization of the neighbouring Balkan and East European regions as regions that are virtual EU member states that have become part of the EU's 'external governance'. The two aspects of analysis - the nature of eroded democracy in ECE and the weakening Europeanization of the Eastern region have been closely interwoven, and together they give a complete picture of the decline of democracy in ECE and its surroundings.

Third, the elaboration of the joint processes of Europeanization and democratization presupposes the specific analysis of social subsystems, in a comprehensive approach starting from the socio-economic changes and progressing through the legal-political transformations to the cultural-civilizational renewal, by investigation of the three major social subsystems. It leads to the principle of simultaneity, since the new 
developments began in parallel in the socio-economic, legal-political and cultural-civilizational subsystems; therefore it is crucial how their interrelationships developed. European studies has relied heavily on the principle of spill-over, the direct effects of changes in one area on the other areas concerned, and the systemic change was conceived as a huge virtuous circle, in which the radical changes in the subsystems reinforced each other in a rather linear, evolutionary development. This easy dream of spill-over automatism has evaporated, and the historical trajectory has shown that, instead of a virtuous circle, it has actually been a vicious circle. Namely, the radical changes in one subsystem have often damaged the others, and they have resulted in much collateral damage in the 'neighbouring' sectors. Altogether, the systemic change would have needed complexity management to coordinate the parallel changes, but the time dimension of radical transformations in these three main subsystems has been different anyway. The crux of the matter is that the collapse of a 'convergence dream' or the failure of the catching-up process has produced mass resentment and finally the victory of (semi-)authoritarian regimes or façade democracies. By describing not only the political but also the socio-economic and cultural subsystems in their interactions, this book deals with the ECE region in a comprehensive way, offering an explanation for the decline and final collapse of ECE democracy in its complexity.

Fourth, turning to the second-stage ECE developments, the book embarks upon the emergence of the New World Order following the global crisis management. In the 2010s there has been a polycrisis in the EU, accompanied and reinforced by the refugee crisis since 2015. It has appeared as a dual crisis in ECE because it has come from both the East and the South, originating from the new aggressive foreign policy of Russia and the Middle East conflicts. The issue of the West Balkan region played an important role for ECE in the 2000s and that of the East European region with the Ukrainian crisis in the 2010s. This has shown, again, the specific character of the ECE region, where large masses of population reacted to the recent wave of international migration in a very different way from that of their fellow citizens in the West. This attitude has been used and abused by the populist elites to create and reinforce an enemy image against the refugees, and to build up a nativist identity politics by blaming 'Brussels' for all the problems in their own countries.

Despite the decline of democracy in the region, followed by its actual collapse in the 2010s, the perspectives of the democratic renewal are outlined in the Postscript from several angles. Beyond the recent federalization drive of the EU that can overcome the recent core-periphery divide with an emphasis on sustainable development, the Postscript 
presents three major arguments for the renewal of democracy: first, the facilitating effect of the 'coming-home' process of emigrants from the West; second, the historical learning process of the ECE populations with the entry of the new, democratically socialized generation; and, third, the prolonged internal crisis and the missing consolidation of the newly emerged ECE authoritarian regimes. The previous decades have been about the long and painful Copenhagen learning process of the EU, discussing the specificities of the regions 'beyond the West'. The next decade will be a test of the learning capacity of the ECE population about redemocratization. With the entry of a new generation, shouting 'Europa, Europa' and carrying EU flags at mass demonstrations against the authoritarian populist regimes, the window of opportunity for democracy renewal has been opened.

The book has been based on a wide range of literature from both international and regional authors. It makes reference to a large database with a series of tables on the most important comparative data using recent contributions of international organizations like Eurostat, the OECD and the World Bank, and major ranking institutions such as Bertelsmann Stiftung (BS), the Economist Intelligence Unit (EIU), Freedom House (FH) and the World Economic Forum (WEF). This material, referred to in the chapters, has been compiled in online appendices and published in an online repository, which is publicly accessible at DOI: 10.13140/RG.2.2.29921.97124. It deals extensively also with the EU framework of ECE developments, especially in the conditions of the emerging New World Order, with new risks and opportunities for both the EU and its ECE member states. The book covers basically the ECE region in its specificity, with a wider outlook on the new member states, but not offering an evaluation of NMS developments in general.

\section{THE DUAL HISTORICAL LEGACY OF CENTRAL EUROPE MOVING BETWEEN EAST AND WEST}

Since both 'history matters' and 'region matters', this book starts with the perspective of the Central European historical region and the impact of the historical traditions on recent developments. This introductory analysis includes the period of state socialism in outline, the direct forerunner of the contemporary period, for its contribution to understanding the systemic change. Western Europe, Central Europe and Eastern Europe have usually been distinguished as the three major regions of Europe. Central Europe with its in-between status may be briefly 
described by the following features: 1) the Central European region has always been on the semi-periphery of the world system, and on the Eastern periphery of Western Europe; 2) the ECE countries have been extremely dependent on changes in the world system, moving historically in cycles of Westernization and Easternization in a state of permanent half-modernization; 3) their societies are fragmented and very heterogeneous, composed of various islands of Western-type and Eastern-type social structures; 4) accordingly, in politics they also have a dual heritage of democratization with civic culture countering the traditions of a strong authoritarian state with its 'subject' mentality; and 5) nowadays they form a zone of young nation states still with deep frustration in their feelings of national sovereignty and longing for the 'European' way of development.

Writing about East-Central Europe, Western experts - and ordinary Westerners, too - are often taken hostage by their Western evidence about ECE, since the ECE countries in many ways look like the West, or 'normal' European countries. Therefore, Western politicians and analysts alike are taken by surprise when they are confronted with the sober reality of the 'abnormal' events in ECE and realize that these countries work in a different way from their Western counterparts. Critical public opinion in ECE calls its own region 'Absurdistan' - the region where everything can happen that would be impossible or unimaginable elsewhere - and therefore this region can only be properly described through a series of paradoxes. In this case disappointed Western experts nowadays may turn to the other extreme about the hopeless 'eternal East' in ECE, without taking the dual - Western and Eastern - face of ECE into consideration. The West in general has been in 'surprise mode' in the last decade in respect of the decline of democracy in ECE, with an eruption of anger that 'We have helped them, but they are still not grateful and have turned against European norms.' This is a situation of mutual misunderstanding, since the Westerners do not take the collateral damage or negative externalities of Europeanization into account, which have been caused by the missing special regional road map for Europeanization and democratization for ECE. The result is a mutual tabuization, as until the 2010s the negative effects of EU membership on ECE were a taboo subject in European studies and in ECE public opinion, and EU documents and analysts avoided any strong and open criticism of ECE governments. The effect of this tabuization is still felt both ways, and it hinders the necessary corrections to the failed historical course to a great extent.

Summarizing the ECE historical trajectory, it has to be mentioned first that since the 16th century - when the West 'discovered the world' - the 
gap between Western Europe and Central Europe has increased more and more. During the revolutionary changes in the West and the refeudalization in Central Europe the distance between the two major regions became wider and wider, both in state and in social structures. The repeated catching-up processes and/or modernization in Central Europe produced their dual face with Western and Eastern features. Central Europe was moving in historical cycles, and sometimes positive, sometimes negative feedback arrived from the West in these alternating virtuous and vicious circles of social and political developments. When the contours of the future nation states were formed in the West, with common public administration and national language, the Polish, Hungarian and Czech kingdoms in Central Europe lost their independence and became part of the Austrian, Russian and German empires. The nation-building process was delayed for many centuries, and the five ECE states became independent only in the 20th century. The birth pangs were great, since these final processes were part of the collapse of the Soviet empire or were connected with the infighting among the countries concerned in the Yugoslav war. Westerners are often surprised by the claims for national sovereignty by the ECE populations, not realizing how young these states are, especially Slovakia and Slovenia. In fact, the ECE countries are still young nation states with a very heterogeneous, fragmented society.

Instead of the social and ethnic homogenization of the long history of Western national states since the early modern age, in Central Europe the large variety of ethnic groups with their particular forms of production, social communities and cultures has been retained historically, and even reinforced, by the dependent economy for Western export. The traditional strong state was the political framework of empires with a feudal or post-feudal social landscape, in which nobility retained political power despite its long and painful degradation, so politics was traditionally a monopoly of rulers. The Hungarian born Károly (Karl) Mannheim has explained that a very fragmented, mosaic society was formed in Central Europe, with strong vertical-social and horizontal-territorial contradictions of synchrony and asynchrony, or the coexistence of social segments from various historical periods and with different socio-economic functions in the social system as a whole. For instance, age-old outdoor animal husbandry in Eastern Hungary coexisted with the modern factories in Budapest in the early 20th century when Mannheim attended university in Budapest.

Looking back to the history of the 16th to 20th centuries, there was a very colourful social landscape in Central Europe, with many islands of premodernity and modernity of very different types. There were various 
cultural traditions and local civilizations, with several ethnicities, settlers or immigrants, including the Roma from early medieval times. The incoming ethnic groups moved around the region, above all after the Turkish invasion, which devastated large parts of Central Europe. The Germans and Jews played a significant role in several modernization waves, first of all in the 19th century. All in all, unlike in Western Europe where ethnic populations existed mostly within national borders, in Central Europe ethnic - and deep socio-cultural - heterogeneity was the rule across the region and provided the starting point for the delayed nation-building process. Hence, the parallel social, political and cultural processes have usually been qualified as organic development in the West, since these factors supported each other, and as inorganic development in Central Europe, where these factors sometimes seriously damaged and disturbed each other.

First of all, this was the case in the 19th century, when the nation building and ethnic revival came at the same time, and they both reinforced and clashed with one another, since the emerging national states were multi-ethnic. The rural and church actors had an important role in the ethnic revival of the autochthonous minorities in the early nation-building process, and in parallel the urban population and Westernized intelligentsia, to some extent of German and Jewish origin, played an eminent role in 'Europeanization', or liberalization and democratization. In ECE the terms 'middle class' and 'intelligentsia' overlapped to some extent, because 'bourgeoisie' had a much wider meaning beyond 'propertied class' (Besitzbürgertum) to 'educated class' (Bildungsbürgertum), and this process was called 'citizenization' in national languages. At the same time this process created deep political and cultural tensions between the modernized or Europeanized urban strata and the traditionally and nationally minded ruling nobility with their deep roots in state administration.

All these processes originating from the delayed development of the nation state and modern society belong to the historical heritage of the ECE countries in their living history. The emergence of the present nation states took place in several steps in the 20th century and was only completed at the time of systemic change. The Western processes of liberalization and especially democratization were not just delayed but distorted in the 19th and 20th centuries, since they were orchestrated by authoritarian states from above and limited by the mosaic societies from below, often with different legal-political systems and voting rights for the various parts of a country and/or different strata of society. All in all, Central Europe historically developed very heterogeneous societies and subcultures, while politically it nurtured the traditions of a strong, 
authoritarian state 'above', a missing network of proper interest representations in the 'middle' and weak civil society 'below'. Finally, the Yalta Agreement pushed the ECE region into its strongest era of Easternization, and the period of state socialism reinforced the negative historical traditions and - by cutting the contacts between the Eastern part of Central Europe and the West - weakened the positive, Europeanized traditions. Soviet rule distorted East-Central European developments to a great extent and made the new wave of Europeanization and democratization in the late 1980s much more difficult.

State socialism has been described in the West in the spirit of an ideological confrontation with 'communism', though it needs a more nuanced characterization in the historical trajectory of continuity and discontinuity. On one side it was the era of the most brutal Easternization in Central European history, but on the other side some of its elements were not completely alien in the earlier history of these authoritarian states. The Easternization, in some respects, just reinforced these negative features of centuries-old Central European history. In fact, East-Central Europe as a region was created by the post-war great power arrangements, cutting the historical region into two parts, since Austria, the most developed part of this region, was given to the West. Although the systemic change meant a profound discontinuity, as a kind of revolution against the former period of state socialism, the signs of continuity have to be exposed as well, because the dual face of earlier Central European history did not disappear overnight. Finally, the continuous features have resurfaced with a vengeance in the 'internal Easternization' of the ECE region in the recent period of hard, authoritarian populism.

For the description of state socialism it has to be noticed that the ECE countries were devastated in the Second World War; for instance, Warsaw and Budapest were ruined. They were given to the Soviet Union in the Yalta Agreement and could not join the Marshall Plan. After a very short democratic period they were subjected in the incoming Cold War to profound Sovietization in all sectors of society. It must have been the most brutal impact of world system changes on Central Europe in its history. In general, unlike the South, the ECE region was left out of Western post-war modernization, and this provides the key to understanding why the ECE countries behaved in a different way in the first period of membership from the Southern member states (which took part in European progress for a long period before joining the EU), since they missed the 'pre-schooling' decades of post-war Europeanization.

First of all, the bipolar world system was, indeed, strictly bipolar, since it separated the two inimical worlds as closed systems. It was imposed on ECE from outside by both actual and virtual violence. This was an 
all-embracing system with complete Easternization in all social spheres from economy to security, organized internationally in Comecon for economic cooperation and in the Warsaw Pact for military security organization. Politically and ideologically, in the early years it was a totalitarian system with terror, turning gradually into an authoritarian system for which the best term is 'state socialism' and not 'communism'. The strengthening and intensification of the Eastern features were not totally alien to ECE going through various historical forms of the authoritarian state, but this was certainly the most radical and brutal time in ECE history. Still it was a particular half-modernization, with some controversial progress, transforming the agrarian societies into industrial societies with some kind of social security and upward mobility, and relatively developed education and cultural systems. This controversial progress continued up to the 1980s, when the historical limits of state socialism appeared inside and outside in the deepening political crisis.

The early signs of systemic crisis came to the surface in the efforts to leave the Soviet camp in the Hungarian revolution of 1956, the Czechoslovak 'Prague Spring' of 1968 and the Polish Solidarity Movement of the 1980s. The Sovietization was so alien to the Central European culture that the culturally oriented political alienation accompanied the whole period. Deep distrust of the imposed culture and ideology ran through state socialism in the form of a 'second society', producing passive resistance networks of social communities with culturally decoded political messages, including a series of typical Central European jokes about the political system. The 1980s were the decade of long-lasting crisis, but the Polish case with its strengthening political confrontation made it clear that the ECE countries could not leave the Soviet camp of their own volition. The erosion of authoritarian rule continued throughout the 1980s, but the collapse of the Bipolar World Order was needed for the big systemic change to end this Easternization cycle.

\section{THE IMPACT OF WORLD SYSTEM TRANSFORMATIONS ON ECE DEVELOPMENTS}

The impact of world system transformations on ECE regional development has been tremendous and overwhelming. Historically it has usually arrived through the West European core to the Central European periphery, so the (West) European framework is the closest approach in this two-level game. This pattern of development has been the longue durée of the Central European region since the formations of the earliest kingdoms in the region; thus in medieval history the three regions of 
Europe emerged: Western Europe, Central Europe and Eastern Europe. These big European regions are 'ideal types' because the borderlines between these regions have changed somewhat throughout history, but nevertheless the cultural-historical legacy and most of the territory of the Central Europe region are rather clear in their 'in-between' position. Unlike Eastern Europe, it belonged to the West European civilization by accepting Western Christianity and by going through the Renaissance, Reformation and Enlightenment and also the 19th- and 20th-century economic, social, political and cultural transformations in its own particular, controversial and belated way, but with the strong feeling of being part of 'Europe'.

The borderlines of the regions also changed after the Second World War. In the case of Central Europe, according to the Yalta Agreement Austria belonged to the West, and the rest was given to the Soviet Union. In fact, the term East-Central Europe was coined in this period, indicating the drastic separation within Central Europe between Austria and its historical 'partners'. The ECE countries emerged after the collapse of the Soviet Union as independent nation states: the Czech Republic (or Czechia), Hungary, Poland, Slovakia and Slovenia. This book covers the region of these five countries, which have been EU member states since 2004. Croatia (CR) is a special case, with its late arrival in the EU and a different historical trajectory in Europeanization and democratization from the other ECE countries. Therefore, in order to be able to describe the ECE story of the last 30 years in depth, Croatia has not been taken into the main body of the book. Altogether, the five countries of the ECE region are only a small part of the EU economically, since the region produces only about 6.0 per cent of gross domestic product (GDP) in purchasing power standards (PPS) of the EU, and all the NMS countries together give 8.5 per cent of EU GDP. The ECE region is slightly more important for its size of population, numbering 66 million people (there are around 100 million people in the NMS countries), and an estimated 10 million people from ECE live and work in the West). It is necessary to note here that the ECE region has many similarities with the other NMS countries in the Baltic and East Balkan area, but this generalization goes beyond the topic of this book.

Historically, Central Europe has always been in between, both structurally and moving between East and West. Central European history has moved in cycles between Westernization and Easternization several times. For the progressive actors in Central Europe, the West - the developed nation states with basic rights and public administrations served as a model to follow. In particular, 19th-century industrialization and modernization conquered hearts and minds in Central Europe. In the 
positive cycle of Westernization there was a dream of Europeanization each time, as in the mid-19th-century revolutions. In general, the challenges for the dramatic changes to Central Europe came from outside, from Western Europe or from the world system. After the Second World War, however, with the Yalta syndrome in the emerging ECE there was deep resentment of being abandoned by the West, and this narrative returns in each crisis situation. Owing to ECE's in-between position and the historical cycles of Westernization and Easternization, the main historical legacy is the dual - Western and Eastern - face of East-Central Europe, and both aspects will be described later in detail through a series of ECE paradoxes.

The ECE contemporary historical trajectory, shaped by the two world wars, departed from internationalization and turned to globalization with the two world system transformations or geopolitical crises of the 1990s and 2010s. Its recent story began with the collapse of the Bipolar World Order in 1989, and continued with the Old World Order and in the current period the transition to the New World Order. The book relies also on the theory of long waves - or Kondratieff cycles - with the assumption of the 'short 20th century', which ended around 1989, giving birth to the OWO and afterwards, at the new turning point, to the NWO. The Bipolar World Order was based on traditional military security with deeply embedded geopolitical considerations. It cut the world system into two inimical parts, with a constant fight for the Third World as well. Although the erosion of the state socialist system was a long process, its collapse came suddenly in the late 1980s. So there was a rapid systemic change in ECE in the conditions of the rising OWO under US dominance. The third wave of democratization opened the age of illusions about the 'liberalization' of the whole world with the extremely simplified theory about the 'end of history'.

With the collapse of the Soviet Union as a world military power the traditional security approach with its geopolitical-geostrategic implications disappeared from theoretical considerations in the OWO. The major change in the OWO was twofold: the rise of the EU as a global power and the growing role of the BRICS group (Brazil, Russia, India, China and South Africa) as new global challengers. Conversely, EuroAtlantic integration in the 1990s in ECE was a big historical achievement, with the periods of anticipative and specific Europeanization before and after 2004. However, in the last decade there has been a process of 'roll-back in Europeanization' in the ECE that has been intensified by the global crisis. This de-Europeanization and de-democratization process has become a significant part of the general polycrisis in the EU. In the 2010s, after a quarter-century of systemic change, the new cycle began in the 
emerging NWO with the age of uncertainty. The last decade of ECE history has been a lost decade in many ways, since recovery from the global financial crisis has taken almost the whole decade and the process of recovery has been overburdened by the refugee crisis.

Nowadays there is a worry that the former type of dependent socioeconomic development in the Soviet camp was switched to another much better, but still dependent - type of development in the EuroAtlantic world. This issue has been a taboo for a long time, even in ECE progressive, Western-oriented circles, but it has erupted strongly in the last few years. No doubt, Western integration meant a big historical achievement but also caused deep distortions in the form of negative externalities from the EU framework in general, or directly from the core countries, given their enormous overweight. There was a massive neoliberal pressure for rapid privatization in the socio-economic transformations, which unleashed a deepening socio-economic polarization. Similarly, the introduction of liberal democracy in the legal-political system was mostly reduced to the formation of big legal institutions (judicial integration), neglecting the formation of participatory society and generating the socio-political exclusion of large masses from public life. In the cultural-civilizational dimension the narrow aspect of modernization patterns dominated, instead of the comprehensive introduction of Western-type social and human capital. Altogether, this will be presented as the ECE type of neoliberal hybrid.

This easy running on the surface of societal changes created good conditions for the Western fallacy, i.e. rapidly reaching the Western model by means of a Western road or in a Western way, but in the belated development there would still have been the need for a special ECE scenario or road map based on the particular nature of the region. The Copenhagen criteria just summarized some very general ideas on democracy and the market economy, but - although the EU provided a cohesion policy with integrative balancing - a region-specific road map of Europeanization and democratization was not elaborated at the time or later. Therefore, some kind of Copenhagen learning process has taken place since then in the EU. Anyway, after the disappearance of this easy dream or wishful thinking, instead of the original Europeanization and democratization narrative there has been a transition to a traditionalistnativist narrative as a counter-action of the populist elite for the disillusioned masses. In this spirit of benevolent neglect on the part of the EU to a region-specific catching-up programme, the patterns of Western political culture could not prevail in ECE under the conditions of increasing polarization and alienation with decreasing systemic trust. 
Originally, the ECE populations reacted to the collapse of authoritarian rule in the early 1990s with a 'revolution of high expectations', so under the label of democracy they expected a Western welfare state overnight; thus after 30 years the disappointment has been tragic. Altogether, the Western fallacy was to assume that the Western road of democratization towards consolidation could be replicated in ECE as well, in both the macro- and micro-structures of a liberal democracy and vibrant civil society. In fact, socio-economic development in the long decades of sustainable economic growth in the consolidated democracies of Western Europe after the Second World War laid a solid foundation for it; moreover, Western civil society itself was the product of an even longer historical development. The political elites of ECE believed that the Eastern copy of the Western road towards liberal democracy would work well in ECE with the establishment of similar formal-legal democratic institutions. This naive optimism based on the Western fallacy prevailed in the 1990s. Although the negative historical trajectory of deconsolidation could have been seen already to some extent in the early 2000s, these worries were swept away by the optimism that EU membership would solve all the basic contradictions both between and within economic, political and social developments, and thus allow the ECE region to swiftly join the core of developed countries and consolidated democracies. Only the global crisis swept away these naive hopes, and thus the public mood, as well as expert view, has turned to deep pessimism.

The big historical turning point in ECE came with the outbreak of the global financial crisis, which separates the history of systemic change into two parts. The decades of transformation crisis and post-accession crisis belong to the first stage and the ECE global competitiveness crisis to the second stage. The key concepts of the first stage are Euro-Atlantic integration, general Europeanization, simultaneous transition, civilizational deficit, the emergence of chaotic democracy and the neoliberal hybrid, which are big successes on the surface and serious wounds to society below the surface. Owing to the obvious failure of the catching-up process and the democratic malaise, the key concepts of the second stage are de-Europeanization and de-democratization caused by the internal Easternization of hard populism with the emerging velvet dictatorships. Finally, further EU federalization in the coming decade and the entry of the new generation in ECE may raise hopes for a redemocratization and re-entry to the EU with an effective membership instead of the present weak and formal membership. 


\section{THE CONCEPTUAL MAP OF SYSTEMIC CHANGE IN ECE}

'Systemic change' has been used in European studies with two meanings: the narrow meaning of drastic rapid changes between the two political and social systems in the early years, and the wider meaning of the long period of political, economic and social transformations, which is an unfinished process. The backsliding of democracy in ECE has lately turned into a topical issue and has usually been analysed only through the formal-legal state institutions in terms of the macro-politics and macroeconomics. The biggest backsliding of democratization, however, has been not so much in the 'official' representative democracy with party systems, but much more in the decreasing public participation of citizens in politics and in the eroding systemic trust of the ECE populations in the ECE political elites. The usual analyses focusing on formal-external Europeanization and democratization have neglected or marginalized internal-substantial Europeanization and democratization. Therefore, the book puts great emphasis on the comprehensive character of the analysis and on the elaboration of system integration and cohesion, involving the entire ECE history, in the description of the decline of democracy and its final collapse in ECE in all three subsystems - the socio-economic, legal-political and cultural-civilizational - in their interrelationships.

The comparative overview of subsystems uncovers the common features of the ECE region despite its individual country specificities. The Eastern enlargement has turned out to be a very mixed success, because Europeanization and democratization have been a very controversial process. System integration in the triple - political, economic and social - transition and through the triple crisis is the starting point for understanding the whole process, including the present social and political situation in ECE. Basically, the entire social system has been rebuilt in ECE in the three subsystems as a triple transition through three consecutive crisis periods in ECE. The triple crisis consists of the transition crisis in the 1990s, post-accession crisis in the 2000s and global crisis in the 2010s, each of them embracing about a decade. Their presentation structured in two stages - with the turning point around 2010 - gives the backbone of the whole book. The ECE region underwent a transformation recession in the early 1990s; with EU entry it fell into a post-accession crisis, which was followed immediately by the global crisis. Altogether, the ECE countries have paid a very heavy social price for the political and economic transformations in this consecutive triple crisis, which has been responsible for the drastic 
backsliding of the new democracies in the 2000s and for the velvet dictatorships of the 2010s.

This book describes the entire process of systemic change in ECE, and consequently the central theme is the system integration with its conceptual frame. This is outlined here based on the ideal types or classical forms of the process, with the timetable of the last three periods or decades to introduce and explain the main ideas and terms of systemic change. These processes are described in detail in the book, elaborated both in their theoretical foundations and in their historical developments. System integration has three dimensions - political integration, social cohesion and human/cultural reproduction - which are summarized below, first in normative terms of polity, politics and policy and then indicating briefly their controversial history in developing the macro-, meso- and micro-levels of systemic change.

\section{(i) Social Integration in the Transformation Crisis of Building the New Polity (Political Integration from Above - Missing Political Participation)}

Systemic change meant complete social disintegration and the need for reintegration, forming a new political architecture (polity) with democratic rules for the political game involving regular, free and fair elections. At the start of democratic transition, new norms and rules were introduced, laid down in the Constitution and accepted by the population; thus they became both legal and legitimate. The democratic polity, or the new institutional architecture, was formed in a very short period, with radical changes at the level of macro-politics. The main issue for the new political order was how the elements of the new system would fit together and/or whether the proper political capital, such as capacity for participation to establish a new political community, would be formed to organize and keep together the entire democratic system. The transformation crisis in the optimistic period of the 1990s was seen as 'normal' for such a big historical change in the perspective of a short democratic transition, which would also create a new civic identity. Although right at the start of this systemic change several kinds of competing civic identities appeared with different socio-political profiles, still there was a basic consensus about the main pillars of the new democratic polity.

The 1990s were dominated by the Western fallacy of an easy dream, which suggested that not only could Europeanization and democratization be introduced in ECE but the repetition of the Western model would be reached in a relatively short period. Nowadays analysts have realized that this over-optimism was not only false but also dangerous, since the 
neglected deep socio-economic and political polarization that had already begun in the 1990s has turned more and more dangerous for Westerntype developments. Formal democratization from above has not become genuine democratization from below, such as would be necessary for the ECE population in creating the proper socio-economic conditions of participatory society as a base for mass political participation in the sustainable democratic polity.

\section{(ii) Social Cohesion in Well-Organized Bonding and Bridging Networks (Social Capital - Socio-Political Participation with Systemic Trust)}

After the early years of democratic transition the problems of social cohesion came more and more to the fore with the extension of 'polity' with the basic constitutional institutions - to 'politics', with a multi-actor political system involving the intensive socio-political activity of citizens in all fields of the social and political system. First of all, the establishing of a socio-economic structure for a dynamic market economy was high on the agenda. The introduction of a well-regulated market economy was necessary to serve as the social foundation of a democratic political system based on the actors of political parties, interest associations and civil organizations. After the transformation crisis, integration mechanisms were required for the inclusion of the new economic, social and political organizations at macro-, meso- and micro-levels in the new system. Supposedly, creating a well-regulated market in the economy leads to the emergence of new social strata with their own interest organizations. Finally, it has to generate the recognition and empowerment both of organized groups and of individual citizens politically as the base for social capital and general trust.

However, this triple transition of parallel economic, social and political transitions proved to be a much longer and more complicated process than the legal-constitutional transition in the transformation crisis. The recombination of the old and new elements took place through the conflictual processes both between and within these particular transitions, and it demanded a constant effort to create social capital and high trust, which eventually failed in the post-accession crisis. In this second decade of democratic transition the EU cohesion perspective was also weakened, and thus the deepening core-periphery divide was already being felt before the global crisis. In the virtuous circle model the economic, social and political transitions support and reinforce each other, whereas in the vicious circle model they block and distort each other. The actual transition process tilted gradually in favour of the vicious circle model, 
with the socio-economic exclusion and increasing polarization of the ECE populations producing low-trust countries with weak social capital.

The economic transition created a dependent dual economy with large masses of losers, and the social transition created a fragmented society with very low social mobility, whereas the political transition created an emptied democracy without the inclusion of citizens in political life. The macro-politics looked fine from the outside, with a democratic façade, but the hardly developed meso-politics and weak civil society showed that the democratic political system was not working properly in a democracy built exclusively from above. In particular, in these politically integrated societies the state became the main factor in the formation of the new social structure, both by the direct means of regular interventions in the market, society and political life and by the indirect means of channelling resources to various social strata following the logic of power politics. As a result, in this formative period the social integration of the newly emerging social strata was dominated by the political integration of the new ruling elite, with wide opportunities for direct state interventions in all fields of society and also for distributing the available resources to the privileged strata.

System integration from this 'process side' of politics can also be described as social capital with its - bonding and bridging - networks, and its historical trajectory showed the same itinerary described above: drastic decline of high expectations for the rapid development of bridging social capital, and a return to bonding networks as a result of the evaporating general social cohesion, with increasing political and cultural heterogeneity. Even the bonding social capital, or belonging to small social groups or communities, was weakened to a great extent because of the permanent restructuring of society, and unexpected moves of political integration from above resulted in mass legal and social desecuritization. Accordingly, systemic trust in the new system was replaced more and more by distrust, in the dimensions both of interpersonal trust (people trusting one another) and of institutional trust (people trusting in institutions).

Thus, the alienation of the population from political elites - and to a lesser extent also from the EU - was already rather high before the outbreak of the global crisis. In the 2000s there were expectations of completing the democratic transition by consolidation with the wide range of new formal and informal institutions supporting each other, but this process turned to deconsolidation. Although EU membership in 2004 was much more than a symbolical turning point in Europeanization and democratization, without a region-specific strategy of catching up it still intensified the problems of the core-periphery divide instead of solving 
them. In the emerging global crisis the drift of ECE from the mainstream was more and more neglected by the EU as its difficulties grew in the late 2000s. Domestically the informal networks of politico-business oligarchs were more and more influential, and they have proved to be the main socio-economic and political actors in the present period.

\section{(iii) The Failure of Policy Making in the New Policies (Human Capital - 'Cultural' Participation in the New EU Civilization)}

Democratic consolidation was conceptualized as the end of systemic change in reaching the phase of advanced, consolidated democracy and sustainable development with the extended reproduction of society, above all in the new policy fields. The ECE countries, however, have not reached this phase even in the third decade of systemic change and in the second stage of development. To the contrary, deconsolidation has been the common theme for their situation in the 2010s. The test case was the global financial crisis, which demonstrated the missing ECE crisis resilience and significantly deepened the core-periphery divide within the EU. Although quantitative catching up showed some success before the global crisis, the 2010s were a time in the EU for qualitative catching up with sustainable development - 'beyond GDP' with the well-being strategy - and the ECE countries were not prepared for that. They have returned to economic growth since the global financial crisis, still in GDP and not in R\&D terms, in the new policy fields of human investment. The challenge in the 2010s has been enlarged social reproduction focusing on human capital, which presupposed a general 'policy' approach with good governance of multilevel and multidimensional policy coordination, while the governance of ECE countries has further declined in the management of global crisis. Good governance presupposes highperforming policy in the socialization-education institutions and the mechanisms for proper labour market management, with high social mobility on one side and civic education (citizenization) or cultural homogenization in basic values, embracing civic culture as an entry to the new European civilization, on the other.

\section{CONCLUSION TO THE INTRODUCTION - THE ECE REGION IN A NUTSHELL}

The most complex presentation of democracy has recently been elaborated by a Varieties of Democracy (V-Dem) project that embraces society as a whole and documents not only the legal-political dimension of 
democracy but also its socio-economic and cultural-human preconditions (Online Appendix 4, Tables VI-XI); the book relies on this concept and dataset to a great extent. However, as a point of departure, the General data (Online Appendix 1, Tables I-XXI) indicate some general features of the ECE region, and its common characteristics from several sides, with a large variety of country developments within this frame, which will be amply discussed later in a much larger overview of the related datasets in this book. These basic data show already that, although the ECE countries have a great deal of variety in terms of size of territory and population, they are close on the level of economic development in GDP terms, and a short overview of their main features would also underline the similarity of their general development.

The first common feature is that the ECE population is placed fairly high on the Human Development Index; in this respect the region belongs to the lower part of the most developed countries. At the same time the utilization of this relatively high human capital is low, and the development of human infrastructure (in education, health care and social services) is lagging very much behind that of the technical infrastructure, which has been the typical case of perverse modernization, with more investment in the 'stones' than the 'brains', or in the roads than the schools (Online Appendix 1, Tables II, VII, VIII, XI).

The second feature is that in an international comparison - despite the deep social polarization - the basic needs on the Maslow pyramid are relatively well served in ECE, but this is less and less so as we move above the basic levels. Therefore, in global statistics (such as those of the United Nations and World Bank), which give much weight to the basic needs in order to embrace the developing countries as well, the ECE region is quite highly placed; however, the contrast between East and West in Europe becomes more visible in those datasets that follow the needs pyramid to its upper levels. This will be referred to as the 'GDP gap' between the GDP level and well-being (Online Appendix 1, Tables X, XVIII-XIX).

The third feature of the ECE region comes from the data on institutional development, which has been the other big bottleneck of international competitiveness. In ECE, institutional reforms took place as a result of outside pressure and appeared from above for the population as an 'alien' force of the state against them. In the waves of modernization the institutional reforms produced a deep split between business and political modernization, with an antagonism between international and domestic institutionalization. The ECE political elites have produced a rather low performance with high corruption that has become the basic feature of the new political system. The historically inherited weakness 
of institutional development has further deepened in the current process of Europeanization and democratization, reducing progress in many ways to a democratic façade in terms of quality of democracy in general and rule of law in particular (Online Appendix 1, Tables V, VI, XIII-XVII, $\mathrm{XXI}$ ).

The fourth feature is the hectic and intensive globalization. Since this region has developed a very high international interdependence, its vulnerability is also very high. Both the advantages and the disadvantages of globalization appear more markedly in ECE than in most countries of Western Europe. First of all, ECE countries' economic globalization is high, their social globalization is somewhat lagging behind, and their political globalization is much less developed than the socio-economic processes would necessitate. The global crisis has hit the ECE region very seriously, and has stopped or at least slowed down the quantitative catching-up process within the EU. Its most drastic effect is the emergence of authoritarian tendencies and systems in the ECE countries in various ways (Online Appendix 1, Tables III-IV).

The fifth feature is that, owing to the frustration of ECE's permanent 'in-between' situation and the ensuing mismatch of the several sectors or aspects of development discussed above, life satisfaction is low in ECE and this is an unhappy region. Altogether in terms of life, opportunities and well-being there is a big contrast between East and West, since social integration or inclusion is weak and there is a huge gap between formal-legal and substantial-actual human rights. This comprehensive feature can be summarized in the contradictions of the macro-processes in social progress on one side and the micro-processes in the lives of citizens as a 'civilizational deficit' on the other. This situation can be captured in the lack of the necessary social and human capital in these 'low-trust countries', with equally low human investment, and thus even the modest achievements of general progress are hardly reflected in the everyday life of human beings (Online Appendix 1, Tables IX, X, XX).

This presentation of the common features of ECE developments leads us to a contrast of the 'hard data' of macro-processes and 'soft data' of micro-processes. Therefore, finally, it is important to emphasize that during these three decades of systemic change a new European civilization emerged, and ECE citizens - in particular the younger generations - are facing the challenge of this new way of life. The ECE crisis is deepest not in economic or political terms but in civilizational terms, as ECE countries witness the emergence of the new West European civilization but remain outsiders in the development of the new era despite their common EU membership. This can be seen in the distinction between cultural and civic types of identity. In general, cultural identity is 
about belonging to a civilization in overall terms of patterns and values, based on historical heritage, for example the 'European identity', while civic identity is connected with a particular socio-political system along the long road of a given civilization. In the ECE case both identities are controversial: the European identity fluctuates in some kind of hate-love relationship with in-between feelings, and the 'civic' identity may turn to an 'uncivil' identity supporting authoritarian regimes and confronting external and internal 'enemies'. Basically the cultural identity in ECE - a firm commitment of ECE populations to being proud European citizens, which is reflected in history as an attachment to European values - has been in contrast to an alienation from Europe in terms of several EU policies because of the relative failure of the catching-up process within the EU. Consequently, there has been an increasing cognitive dissonance between the European cultural identity and the national civic identity that has led to serious disturbances in the behaviour of ECE countries in the EU. This intensifying cognitive dissonance has also shown a clear generation gap with the entry of a new generation that is more socialized in the new European civilization and way of life.

This present stage of deconsolidation or disintegration in ECE has been dealt with in this book from the point of view of the systemic approach of democracy, in both its software and its hardware, as a transition from political 'event history' to social and cultural history, from formal to informal institutions, from legal rules to patterns of political culture, from welfare to well-being, and from 'economic' (physical or business) capital to 'cultural' (human and social) capital. This is the model of the Europeanization of social sciences, in particular political science, in the late 20th century after a long period of Americanization. This divergence in the concept of democracy can also be seen in the ranking institutes. Freedom House, with its concept of 'free', indicates an outdated model of the free world and a narrow concept of modernization, while the Economist Intelligence Unit, World Economic Forum and Bertelsmann Stiftung offer a much wider view, with open criticism of the US concept that allows the proper description of ECE developments in their complexity.

In the presentation of ECE contemporary history, public opinion surveys are relevant, in the spirit of 'Let the people speak for themselves.' The Eurobarometer (EB) surveys are of basic importance, although not helpful enough to capture the specificity of the ECE region, since its questions have tried to cover the common features of 28 member states, and therefore they are necessarily over-generalized and in many ways do not reach below the surface. This relates mostly to the NMS case in general and the ECE case in particular, especially in terms of 
discovering region-sensitive cognitive dissonance and paradoxes. The main kind of cognitive dissonance in ECE has been between the general-symbolical support of Europeanness (feeling of being proud European citizens, and membership of the EU) and sharp criticism of many particular EU policies (recently refugee crisis management or the so-called EU democratic deficit). Understandably, the EB questions cannot be region-sensitive for the various regions of the EU, but they have some 'path dependence', captured by the tradition since the 1970s, and tend to reflect the standards of the original and/or big member states. It is a major problem in relation to discovering the special 'in-between' situation of the ECE that can only be captured through the paradoxes, going below the surface of the very general questions to the more concrete issues in detail. These issues often show that the 'positive' answer to the 'first big question' of a survey is misleading, since the following detailed answers on the same groups of issues tend to be 'negative' and reveal the naked reality.

The region-sensitive approach is eminently important for pointing out the common features of the ECE region and the varieties of its individual countries, since with some arbitrariness it is quite easy to collect data for both the complete unity and the profound diversity of ECE countries. However, the 'multilevel', in-depth analysis of the data reveals that in a 'cluster' analysis there are common problems and worries behind the seemingly diverging situation of the individual countries. This is typically shown in the Czech and Slovak cases, where the first big answers of public opinion surveys sometimes present a relatively satisfied country, unlike the Hungarian, Polish and Slovenian cases, but the following detailed answers uncover their deep dissatisfaction with the situation in the country.

These huge tensions within the perceptions of ECE citizens about their countries' situation, however, are characteristic for all ECE countries, and thus the region-specific public opinion surveys are much more helpful and indicative than the general EB series. They indicate the turning points in contemporary ECE history, as the Pew data of the late 2000s reveal the credibility crisis, and uncover the complexity of the situation and also that of public opinion about it - with its multiple contradictions and main trends. It is similar with the current Globsec data about the 'family quarrels' in the Visegrad states, which do not disturb their common position on basic matters, for example the refugee crisis. All these mixed messages in the region-specific surveys represent the same Central European dilemma of the 'in-between situation', between nostalgia for the past and hope for the future, or between path dependence and 
emerging opportunities. These mixed messages appear also in the contradictory attitudes towards the EU, and domestic development as a combination of strong commitment with ambivalent views, vague ideas and blurred perceptions.

The drastic changes in ECE in the last decade necessitate a radical reconceptualization, since new analytical devices are needed to theorize the new conflicts between the core and the periphery. In my view there are three steps of presentation to discover the divergence of ECE states from EU mainstream developments: 1) the absolute civilizational (socioeconomic and cultural) deficit before the accession and the emerging relative institutional deficit since the accession; 2) the growing gap between formal-legal external Europeanization and substantive internal Europeanization; and 3) the following de-Europeanization and dedemocratization, leading to the collapse of the ECE democratic order. The distinction between the absolute (historical) and relative (EU-related) deficit and the ensuing distinction between external and internal Europeanization were neglected for a long time in European studies; hence the present situation of deep conflict has come as a surprise for the EU institutions because of their optimistic and evolutionary approach.

\section{SELECTED PUBLICATIONS OF ATTILA ÁGH (1998, 2014-2018)}

Ágh, Attila (1998a), Emerging Democracies in East Central Europe and the Balkans, Cheltenham, UK and Lyme, NH, USA: Edward Elgar Publishing.

Ágh, Attila (1998b), The Politics of Central Europe, London: Sage.

Ágh, Attila (2014a), 'The fall of the Berlin Wall and European politics: Perspectives of new Europe in the early twenty-first century', in José Magone (ed.), Routledge Handbook of European Politics, London: Routledge, pp. 116-131.

Ágh, Attila (2014b), 'The roller-coaster ride of the Hungarian administrative elite: Politico-administrative relations in East-Central Europe', Revue française d'administration publique, 14 (151-152), 663-680.

Ágh, Attila (2015a), 'The transformation of the Hungarian party system: From the democratic chaos to the elected autocracy', Südosteuropa, 63 (2), 201-222.

Ágh, Attila (2015b), 'The triple crisis in the new member states: The historical trajectory of NMS-8 in the past quarter century', Southeastern Europe, 39 (3), 294-317.

Ágh, Attila (2015c), 'Bumpy road of civil society in the new member states: From the state capture to the renewal of civil society', Politics in Central Europe, 11 (2), 7-21. 
Ágh, Attila (2016a), 'The increasing core-periphery divide and the new member states: Diverging from the European Union's mainstream developments', in José Magone, Brigid Laffan and Christian Schweiger (eds), Core-Periphery Relations in the European Union, London: Routledge, pp. 117-129.

Ágh, Attila (2016b), 'The decline of democracy in East-Central Europe: Hungary as the worst-case scenario', Problems of Post-Communism, 63 (5-6), 277-287.

Ágh, Attila (2016c), 'Rocky road of Europeanization in the new member states: From democracy capture to the second try of democratization', Polish Sociological Review, 193 (1), 71-86.

Ágh, Attila (2017a), 'Cohesive Europe or core-periphery divide in the EU28: The regional challenge of dual crisis in the new member states', Journal of Comparative Politics, 10 (1), 4-24.

Ágh, Attila (2017b), 'EU polycrisis and hard populism in East-Central Europe: From the Copenhagen dilemma to the Juncker paradox', Politics of Central Europe, 13 (2-3), 7-32.

Ágh, Attila (2017c), 'The declining systemic trust in the NMS political elites: The divergence between East-Central Europe and the Baltic states', Baltic Journal of Political Science, 6 (6), 27-49.

Ágh, Attila (2018a), 'External and internal Europeanization in East-Central Europe: The new populist parties and deconsolidation in the 2010s', Journal of Comparative Politics, 11 (1), 12-32.

Ágh, Attila (2018b), "The "populist explosion" in the West and its effect on the NMS', Czech Journal of Political Science, XXV (1), 45-63.

Ágh, Attila (2018c), 'Decline of democracy in the ECE and the core-periphery divide: Rule of law conflicts of Poland and Hungary with the EU', Journal of Comparative Politics, 11 (2), 30-48.

Ágh, Attila (2018d), 'The Hungarian party system from soft to hard populism', in Marco Lisi (ed.), Party System Change, the European Crisis and the State of Democracy, London: Routledge, pp. 137-154.

Ágh, Attila (2018e), "The dual crisis and "regionalization" in the Visegrád states', in Christian Schweiger and Anna Visvizi (eds), Central and Eastern Europe in the EU: Challenges and Perspectives under Crisis Conditions, London: Routledge, pp. 177-189.

Ágh, Attila and Attila Kovács (2016), 'EU cohesion policy in the Eastern Partnership region: A case of external Europeanisation', in Simona Piattoni and Laura Polverari (eds), Handbook on Cohesion Policy in the EU, Cheltenham, UK and Northampton, MA, USA: Edward Elgar Publishing, pp. 399-412. 